\title{
Downregulated lincRNA HOTAIR expression in ovarian cancer stem cells decreases its tumorgeniesis and metastasis by inhibiting epithelial-mesenchymal transition
}

\author{
Jing Wang ${ }^{1 *}$, Dengyu Chen ${ }^{2,3 \dagger}$, Xiangfeng He ${ }^{4 \dagger}$, Yuxia Zhang ${ }^{1,2}$, Fangfang Shi ${ }^{2,5}$, Di Wu ${ }^{1,2}$, Junsong Chen ${ }^{2}$,
} Ying Zhang ${ }^{2}$, Fengsu Zhao ${ }^{2}$ and Jun Dou ${ }^{2 *}$

\begin{abstract}
Background: Emerging evidence indicates that dysregulated long intervening non-coding RNA (lincRNA) HOTAIR correlates highly with tumor invasion and metastasis but a link between the high expression of HOTAIR and the metastatic cascade of cancer stem cells (CSCs) needs to be further studied. The purpose of this study was to investigate the effect of down-regulated HOTAIR expression on tumorgeniesis and metastasis of epithelial ovarian cancer (EOC) CSCs. CD $117^{+}$CD $44^{+}$CSCs were isolated from human EOC SKOV3 cell line by using a magnetic-activated cell sorting system, and were then transfected with the expression vector-based small hairpin RNA targeting HOTAIR; the stably transfected cells were selected for the study. Colony-forming, wound-healing, cellular metastasis and tumorigenicity assays were performed.
\end{abstract}

Results: The results demonstrated that the HOTAIR expression in clinical EOC tissues and SKOV3 CD $117^{+} \mathrm{CD} 44^{+} \mathrm{CSCS}$ was higher than in SKOV3 tumor tissues and non-CD $117^{+} \mathrm{CD} 44^{+} \mathrm{CSC}$. The CD $117^{+} \mathrm{CD} 44^{+}$-shHOTAIR showed an inhibited HOTAIR expression, reduced cell migration and invasion than $\mathrm{CD} 117^{+} \mathrm{CD} 44^{+}$- scramble, suggesting the inhibition of an epithelial-mesenchymal transition. Moreover, the downregulated HOTAIR expression in CD117 ${ }^{+} \mathrm{CD}_{4}{ }^{+} \mathrm{CSC}$ s significantly decreased the tumor growth and lung metastasis in xenograft mice.

Conclusion: Our findings demonstrated the shHOTAIR-mediated down-regulation of the HOTAIR expression in CD $117^{+}$CD $44^{+}$CSCs can be a promising new opportunity for future clinical trials.

Keywords: Epithelial ovarian cancer, Cancer stem cells, LincRNA HOTAIR, Epithelial-mesenchymal transition, RNA interference

\section{Introduction}

Human epithelial ovarian cancer (EOC) is one of malignant tumors in gynecological cancers and currently remains to be the number one the first leading cause of cancer-related deaths in women due to factors such as failure for its early dectection and diagnosis, its proneness to pelvic and peritoneal metastasis, and its resistance to

\footnotetext{
* Correspondence: njwjdj@sina.com; njdoujun@seu.edu.cn

${ }^{\dagger}$ Equal contributors

'Department of Gynecology \& Obstetrics, Zhongda Hospital, School of Medicine, Southeast University, Nanjing 210009, China

${ }^{2}$ Department of Pathogenic Biology and Immunology of School of Medicine, Southeast University, Nanjing 210009, China

Full list of author information is available at the end of the article
}

chemotherapy after recurrence. Although many studies have been published in the past decade and have contributed to the advance of the knowledge in this field, the complex biology of EOC is still insufficiently understood $[1,2]$. Therefore, more recent studies have focused on the molecular mechanisms underlying the EOC progression and the new strategies for early clinical diagnosis and effective therapy $[3,4]$.

Recent studies have demonstrated that cancer stem cells (CSCs) are responsible for tumour-initiating potential, metastasis and eventual relapse. Thus, the treatments that target CSCs may lead to the discovery of effective methods to eradicate the malignant tumor cells [5-7]. 
Emerging evidence supports that long intervening non-coding RNAs (lincRNAs) play a critical role in regulating cellular processes such as differentiation, proliferation, and metastasis [8,9]. HOX transcript antisense RNA (termed HOTAIR), one of lincRNAs, functions in epigenetic regulatory processes, interacts with polycomb repressive complex 2 and is required for histone H3 lysine-27 trimethylation of the $H O D$ locus. In addtion, HOTAIR has been strongly associated with the invasion and metastasis of cancer cells [10]. Dysregulation of lncRNA HOTAIR has been considered a primary feature of several human cancers including breast cancer $[10,11]$, hepatocellular carcinoma [12,13], colorectal cancer [14], pancreatic carcinomas [15], gastrointestinal stromal tumors [16], and human EOC $[17,18]$. Of the many functions of HOTAIR, as tumor regulatory factors, the one for silencing HOTAIR transcription in CSCs has remained insufficiently understood $[17,19]$. For this reason, we investigated whether the downregulated HOTAIR expression would decrease the human EOC SKOV3 $\mathrm{CD} 117^{+} \mathrm{CD} 44^{+} \mathrm{CSC}$ metastasis by inhibiting epithelial- mesenchymal transition (EMT) in vitro, as well as cellular tumorigenicity in nude mice. The data from our current study showed that epigenetic silencing of lncRNA HOTAIR in SKOV3 $\mathrm{CD} 117^{+} \mathrm{CD} 44^{+} \mathrm{CSCs}$ resulted in reduced cellular tumorgeniesis and metastasis in mouse model. This fingings suggested that the streatgy of downregulating the HOTAIR expression may serve as a potential anti-cancer regimen for inhibiting EOC CSC's invasiveness and metastasis. Future investigations of this possibility are fully warranted.

\section{Materials and methods Cell line}

SKOV3 cell line was acquired from an ovarian cancer patient, which is a well-established ovarian cancer model system; the line was purchased from the Cellular Institute in Shanghai, China. Cells were cultured in complete media consisting of RPMI 1640, 2 mM L-glutamine, 100 $\mathrm{U} / \mathrm{ml}$ penicillin, $100 \mu \mathrm{g} / \mathrm{ml}$ streptomycin, and $10 \%$ fetal bovine serum. The medium was refreshed every 3 days to maintain adherent cells. When the SKOV3 cells reached $90 \%$ confluence, cells were harvested with $0.25 \%$ trypsin $-1 \mathrm{mM}$ EDTA (Sigma-Aldrich, St. Louis, MO, USA) treatment for $2 \mathrm{~min}$.

\section{Isolation of $\mathrm{CD} 44^{+} \mathrm{CD} 117^{+}$cells and identification of cell phenotype}

$\mathrm{CD} 44^{+} \mathrm{CD} 117^{+}$cells were sorted from the SKOV-3 cell line by using the magnetic-activated cell sorting (MACS, Miltenyi Biotec., Bergisch Gladbach, Germany). First, CD $44^{+}$subsets were isolated by using the mouse antihuman CD44 antibody coupled to magnetic microbeads (code number:130-095-194, antibody dilution,1:20, Miltenyi Biotec., Bergisch Gladbach, Germany) and followed by the magnetic column selection or depletion. Second, the resulting cells were then depleted of CD $117^{-}$subsets by using mouse antihuman CD117 antibody coupled to magnetic microbeads (code number:130-091-332, antibody dilution,1:20, Miltenyi Biotec., Bergisch Gladbach, Germany), and we named the $\mathrm{CD} 44^{+} \mathrm{CD} 117^{+}$cells for the EOC cancer stem cells as 'EOC SKOV-3 CD44 ${ }^{+} \mathrm{CD} 117^{+} \mathrm{CSCs}$ ' [20-22]. The isolated cells were placed in stem cell culture medium by resuspension in serumfree DMEM/F12 supplemented with $5 \mu \mathrm{g} / \mathrm{mL}$ insulin (Sigma-Aldrich, Missouri, USA), $20 \mathrm{ng} / \mathrm{mL}$ human recombinant epidermal growth factor (Invitrogen, CA, USA), $10 \mathrm{ng} / \mathrm{mL}$ basic fibroblast growth factor (Invitrogen, CA, USA) and $0.5 \%$ bovine serum albumin (Sigma-Aldrich, Missouri, USA) [23,24]. The isolated $\mathrm{CD} 44^{+} \mathrm{CD} 117^{+}$cells were further identified by using flow cytometer (FCM, BD, USA) [25].

\section{The short hairpin RNA sequence design}

A short hairpin RNA sequence of IncRNA HOTAIR was designed based on the HOTAIR RNA sequence (Gene ID: 100124700) by using the siDESIGN design software (Dharmacon, http://www. thermoscientificbio.com/design-center/) and the Block-iTTM RNAi Designer (Invitrogen, Grand island, NY) as well as BLAST (http:// www. ncbi. nlm.nih. gov/BLAST). The target sequence site for HOTAIR shRNA includes 19 base pairs of the HOTAIR RNA sequence. In addition, one scramble sequence was designed as a negative control. The shRNA sequences are as follows: pSUPEREGFP1-HOTAIR-shRNA (pSUPER- EGFP1-shHOTAIR), Forward 5'-GATCCCCGAACGGGAGTACAGAGAGATT CAAGAG A TCTCTC TGTACTCCCGTTCTTTTTGGA AA-3'; antisense, $5^{\prime}$-AGCTTTTCCAAAAAGAACGGG A GTACAGAGAGATCTCTTGAATCTCTCTGTACTCCCG TTCGGG-3';scramble-siRNA: sense, 5' - GATCCCCTTC TCCGAACGTGTCACGTTTCAAGAGAACGTGACACG TTCGGAGA ATTTTTGG A AA-3'; antisense, 5'-AGCT TTTCCAAAATTCTCCGAACGTGTCACGT-TCTCTTG AAACGTGAC ACGTTCGGAGAAGGG-3'. All the primers were synthesized by Gene and Technology of China in Shanghai [10].

\section{Construction of pSUPER-EGFP1-HOTAIR -shRNA and production of stably transfected clones}

A pSUPER-EGFP1 (enhanced green fluorescent protein 1) vector was used to construct recombinant. The recombinant pSUPER-EGFP1-HOTAIR-shRNA (shHOTAIR) was developed as previously describled $[10,26]$. A pSUPEREGFP1-scrambled shRNA (Scramble-HOTAIR) was used as a negative control. These recombinants were verified by the analysis of endonuclease digestion and sequencing. The shHOTAIR and SCHOTAIR were respectively transfected into $\mathrm{CD} 44^{+} \mathrm{CD} 117^{+} \mathrm{CSC}$ and the stably transfected clones were selected with G418 (Clontech, CA). ShHOTAIR- 
expressing and Scramble-HOTAIR-expressing clones were labeled ${ }^{\prime} \mathrm{CD} 44^{+} \mathrm{CD} 117^{+}$shHOTAIR'and ${ }^{\circ} \mathrm{CD} 44^{+} \mathrm{CD} 117^{+}$ scramble, respectively.

\section{Clinical samples}

Four fresh surgical tissue samples of EOC patients with a median age of 55 years (age range 45-63) were collected at the Department of Gynecology \& Obstetrics, Zhongda Hospital, Medical School, Southeast University between March 2012 and October 2012. The four surgical tumor samples used in this study (designated T1-T5) were categorized as malignant Fesddration Internationale des Gynaecologistes et Obstetristes (FIGO) stage IIIII serous adenocarcinomas. All samples were stored immediately in liquid nitrogen until analysis [21].

\section{Quantitative RT-PCR of HOTAIR}

Total RNA was extracted from the SKOV-3 CD $44^{+} \mathrm{CD}$ $117^{+}$CSCs or SKOV-3 cells or microdissected tumor tissue samples of EOC patients by using a Qiagen RNeasy Kit (Qiagen, Valencia, CA, USA) following by the manufacturer's protocol. A single-stranded cDNA was prepared by the using SuperScript III reverse transcriptase (Invitrogen). Quantitative real-time reverse transcription-PCR (qRTPCR) was carried out on an ABI step one plus real-time system (Applied Biosystems, USA). The cDNAs were amplified by PCR with primers as follows: HOTAIR: sense, 5'-GGTAGAAAAAGCAACCACG AAGC-3'; antisense, 5'-TTGGGGAAGCA TTTT CTGAC-3'; $\beta$-actin (sense, 5'-GGACTTCGAG CAAG AGATGG-3'; antisense, 5'-AGCACTGT GTTGGCGTACAG-3'). U6-RT Primer, 5'-GTCGTATCCAG TGCAGGGTCCGAGGTATTCGCA CTGGATACGACAAATATGGAAC-3'; sense, 5'-TGCGG GTGCT CGCTTCGG CAGC-3'; URP (Universal Reverse Primer), 5'-CCGGCAGGGTCCGAGGT-3'; E-cadherin: sense, 5'-TACACTGCCCAGGAGCCAGA-3'; antisense, 5'-TGGCACCAGTGTCCGGATTA-3'; Vimentin: sense, GGAACAGCATGTCCAAATCG; antisense, GCACCT GTCTCCGGTACTCA. The mRNA levels of the genes of interest were expressed as the ratio of each gene of interest to $\beta$-actin or U6 mRNA for each sample. The comparative $C t(\Delta \Delta \mathrm{Ct})$ method was used to determine the expression fold change $[27,28]$.

\section{Colony forming assay}

The colony formation ability of SKOV3 $\mathrm{CD} 117^{+} \mathrm{CD}$ $44^{+}$-shHOTAIR was investigated. A colony with a diameter larger than $75 \mu \mathrm{m}$ or having more than 50 cells was counted for 1 positive colony according to our previous report [20]. The plate clone formation efficiency was calculated as (number of colony/number of cells inoculated) $\times 100 \%$.

\section{Cell migration assay}

To determine the role of down-regulated HOTAIR expression on migration, SKOV3 $\mathrm{CD} 117^{+} \mathrm{CD} 44^{+}$- shHOTAIR were used in the wound healing assay. Briefly, SKOV3 CD117 $\mathrm{CD} 44^{+}$-shHOTAIR or SKOV3CD $117^{+} \mathrm{CD} 44^{+}$-scramble were plated in 6-well plates $\left(5 \times 10^{5}\right.$ cells per well) to form a monolayer one day before the assay; non-adherent cells were removed by PBS washing. On the following day, a uniform scratch was made down in the center of the well using a sterile micropipette tip. The distance travelled by the cells was measured between the two boundaries of the acellular area at $0,24,48$ and 96 hours respectively, after incubation. Each experiment was performed in triplicate [29].

\section{Cell invasion assay}

The invasion ability of SKOV3 $\mathrm{CD} 117^{+} \mathrm{CD} 44^{+}$-shHOTAIR or SKOV3 $\mathrm{CD} 117^{+} \mathrm{CD} 44^{+}$-scramble was evaluated by using the transwell invasion assay as previously described [30]. Briefly, the transwell inserts with $8 \mu \mathrm{m}$ pores were coated with Matrigel $(20 \mu \mathrm{g} /$ well; Becton Dickinson, Waltham, MA, USA); cells were seeded in the upper chamber in RPMI1640 medium supplemented with 10\% fetal bovine serum. After incubation at $37^{\circ} \mathrm{C}$, the cells that invaded to the lower surface of the Matrigel-coated membranes were fixed with $70 \%$ ethanol and stained with trypan blue; the cells from five randomly selected fields were then counted under a light microscope.

\section{Western blotting analysis}

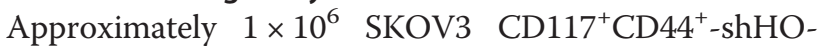
TAIR or SKOV3CD $117^{+} \mathrm{CD} 44^{+}$-scramble were collected and lyzed in the protein extraction buffer (Novagen, Madison, WI, USA), and $12 \%$ sodium dodecyl sulfatepolyacrylamide gel electrophoresis was performed and proteins $(10 \mu \mathrm{g} /$ lane $)$ were loaded by following the pulished papers $[6,31]$. The rabbit antibody specific to human E-cadherin (code number: 31955) or Vimentin (code number: 57415) was used in the assay (Bioworld Technology, Dublin, OH, USA). The antibody dilution was 1: 1000 .

\section{Tumorigenicity of shHOTAIR-SKOV3 $\mathrm{CD} 117^{+} \mathrm{CD} 44^{+} \mathrm{CSCs}$ in an xenograft mice}

Balb/c nude mice (female, weight: 16-18 $\mathrm{g}$ and age between 5 and 6 weeks) were ordered from the Animal Center of Yang Zhou University of China and were raised under sterile conditions at the Experimental Animal Center, Medical School of Southeast University. The experiments were performed in compliance with the guidelines of the Animal Research Ethics Board of Southeast University, China. Twelve nude mice were randomly divided into two groups of equal size (six per group): the SKOV3 CD $117^{+} \mathrm{CD} 44^{+}-$ shHOTAIR group, and the SKOV3CD $117^{+} \mathrm{CD} 44^{+}$-scramble group. The nude mice was subcutaneously injected in 
the back with $5 \times 10^{4}$ SKOV3 $\mathrm{CD} 117^{+} \mathrm{CD} 44^{+}$-shHOTAIR or SKOV3 $\mathrm{CD} 117^{+} \mathrm{CD} 44^{+}$-scramble. Tumor formations in each mouse were monitored every three days by taking 2dimensional measurements of individual tumors from each mouse [32].

\section{Lung histopathology}

Lung tissues were removed from the xenograft mice, fixed in $10 \%$ formalin, and then embedded in paraffin. Lung tissue sections of $4 \mu \mathrm{m}$ thin were cut and mounted on SuperFrost Plus glass slides; the tissues were fixed in methanol and stained in hematoxylin and eosin (HE). The slides were viewed under a Zeiss Axioplan light microscope at a magnification of $\times 200$ [33].

\section{Statistical analysis}

Values of interest were presented as the mean plus or minus two standard deviation. Statistical comparisons were performed using the Student's $t$-test method. Results for all analyses with a $P$ value $<0.05$ indicate the statistically significant differences.

\section{Results}

\section{HOTAIR expression in EOC tissues and SKOV3} $\mathrm{CD} 117^{+} \mathrm{CD} 44^{+} \mathrm{CSCs}$

In this study, we first wanted to know whether the HOTAIR expression existed in human EOC tissues and in tumor bearing mice injected with SKOV3 cells. The result of qRT-PCR in Figure 1A shows that the HOTAIR expression not only existed in the EOC patient's tumor tissues but its expression was significantly increased compared with SKOV3 tumor tissues in nude mice $(p<0.001)$. Next, we further investigated whether the HOTAIR expression was increased in SKOV3 $\mathrm{CD} 117^{+} \mathrm{CD} 44^{+} \mathrm{CSCs}$ compared with SKOV3 non$\mathrm{CD} 117^{+} \mathrm{CD} 44^{+} \mathrm{CSCs}$ in order to find a novel therapeutic target for theatment of EOC. As Figure 1B portrays, the $\mathrm{CD} 117^{+} \mathrm{CD} 44^{+}$cells, termed $\mathrm{CD} 117^{+} \mathrm{CD} 44^{+} \mathrm{CSCs}$ as described in our previous reports [6,22], were isolated by
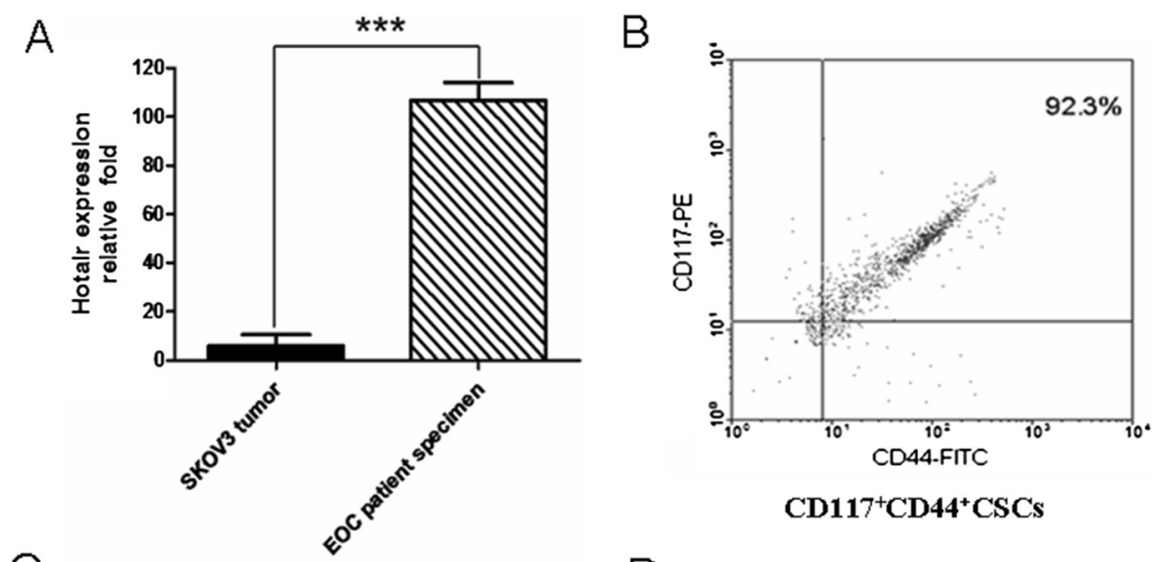

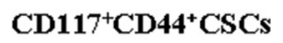

C

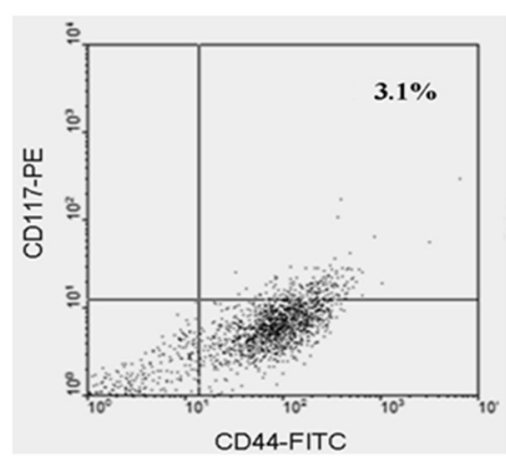

SKOV3 cells
$\mathrm{D}$

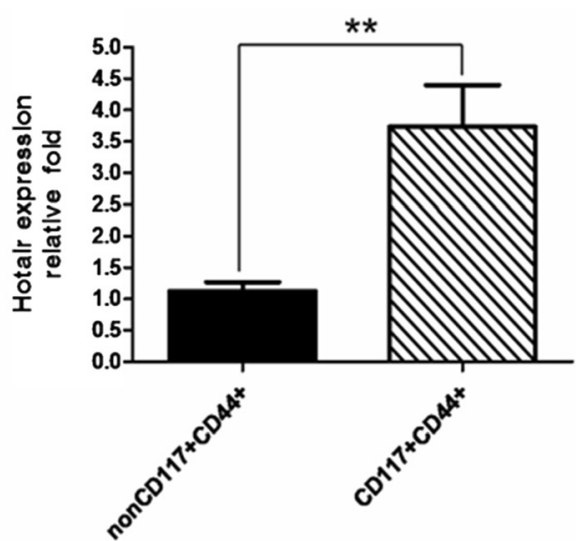

Figure 1 Detection of HOTAIR expression in tumor tissues and CD $117^{+} \mathrm{CD} 44^{+} \mathrm{CSC}$ s identified by qRT-PCR and FCM. A. The HOTAIR expression in four patient's EOC tissues and six SKOV3 tumor tissues in the mice tested by qRT-PCR. B and $\mathbf{C}$. The cell phenotype of CD44 ${ }^{+} \mathrm{CD} 117^{+}$cells sorted from the SKOV-3 cells by using the magnetic-activated cell sorting system (B) and the SKOV-3 cells (C) were analyzed by FCM, indicating $92.3 \%$ and 3.1\%, respectively, of the double positive phenotypes of CD44 and CD117 in sorted cells and SKOV-3 cells. D. QRT-PCR analysis of the HOTAIR expression in both the $\mathrm{CD} 117^{+} \mathrm{CD} 44^{+}$cells and the non $\mathrm{CD} 117^{+} \mathrm{CD} 44^{+}$cells. ${ }^{* *} p<0.01$ and ${ }^{* *} p<0.001$ were calculated by using the Student's $t$ test method, referring to the differences as indicated. 
MACS, validated by FCM, and the purity of $\mathrm{CD} 117^{+} \mathrm{CD} 44^{+}$ cells reached $92.3 \%$, but there were only $3.1 \%$ of $\mathrm{CD} 117^{+}$ $\mathrm{CD}_{4}{ }^{+}$cells in SKOV3 cells (Figure 1C). Figure 1D shows the high expression of HOTAIR in CD $117^{+} \mathrm{CD} 44^{+} \mathrm{CSCs}$ in contrast with non-CD $117^{+} \mathrm{CD} 44^{+} \mathrm{CSCs}(p<0.01)$.

\section{Effects of down-regulated HOTAIR in SKOV3 cells on the ability of migration and invasion}

Since HOTAIR plays important regulatory roles in the malignant tumor progression through regulating cell cycle, apoptosis, invasion and metastasis, a high expression of HOTAIR correlates highly with some epithelial tumor metastasis and invasion [10,11]. Therefore, we investigated whether this correlation was changed when the HOTAIR expression was down-regulated in the SKOV3 cells. According to the previous report [10], we synthesized siHOTAIR 5'-GAACGGGAGUACAGA GAGAUU-3' that was transfected into the SKOV3 cells. Indeed, the HOTAIR expression was markedly decreased compared with the SKOV3 cells $(p<0.05)$ 24 hours after the cells were transfected with siHOTAIR 50 nanomolar (Figure 2A). This efficacy led to the observations that the E-cadherin expression (epithelium features) was obviously increased and the Vimentin expression (mesenchymal features) was markedly decreased (Figure 2B-D). In addition, Figure 2E and G show that the migration and invasion ability of the SKOV3 cells was also remarkablely decreased compared with the SKOV3

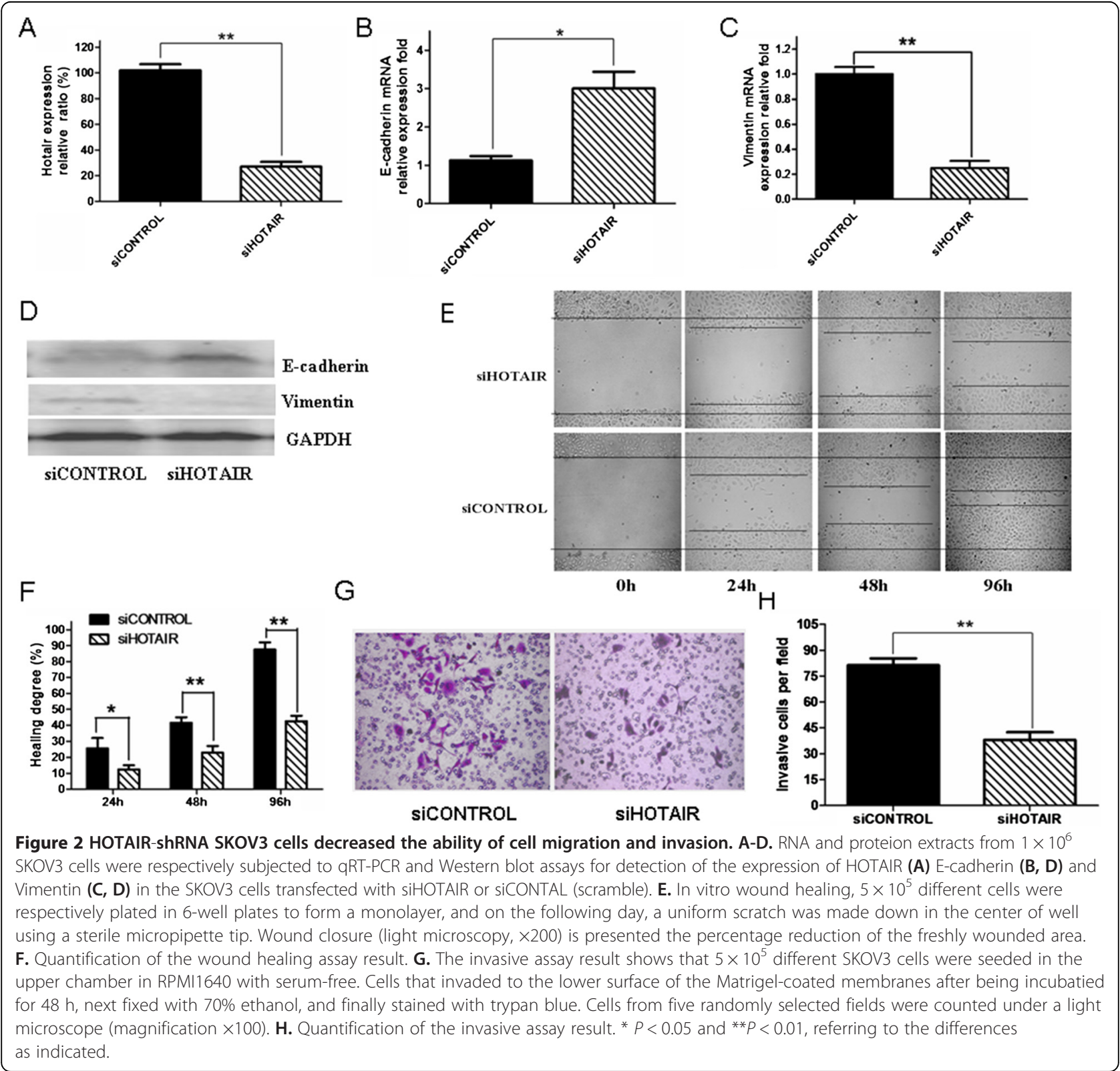


cells transfected with scramble-HOTAIR, as is shown in Figure $2 \mathrm{E}-\mathrm{H}(p<0.05$ or $p<0.01)$.

\section{Effect of down-regulated HOTAIR in CD $117^{+} \mathrm{CD} 44^{+} \mathrm{CSCs}$ on the ability of colony, migration and invasion}

To stably reduce the HOTAIR expression, we next developed the recombinant shHOTAIR to investigate the effect of down-regulated HOTAIR expression on the ability of colony, migration and invasion in SKOV3 $\mathrm{CD} 117^{+} \mathrm{CD} 44^{+} \mathrm{CSC}$ in vitro. The validated $\mathrm{CD} 117^{+} \mathrm{CD} 44^{+} \mathrm{CSC}$ by $\mathrm{FCM}$ were transfected with the recombinant shHOTAIR (Figure 3A, right-panel) or scrambled HOTAIR (Figure 3A, left-panel), which were observed under a fluorescence microscope (toppanel) and under a light microscope (bottom-panel). The stably transfected $\mathrm{CD} 117^{+} \mathrm{CD} 44^{+}$-shHOTAIR decreased the HOTAIR expression by $54 \pm 5 \%$ (Figure $3 \mathrm{~B}$ ) and reduced its colony forming rate $(18 \pm 6 \%)$ compared with the $\mathrm{CD} 117^{+}$ $\mathrm{CD}_{4} 4^{+}$scramble $(46 \pm 7 \%$, Figure $3 \mathrm{C})$; the differences were statistically significant $(p<0.01$, Figure $3 \mathrm{~B}$ and D). Figure $4 \mathrm{~A}$ exhibits the image of the cell migration results tested by the wound healing assay. Cell migration rates at 24 and 48 hours showed a statistically significant reduction in $\mathrm{CD} 117^{+} \mathrm{CD} 44^{+}$ -shHOTAIR compared with $\mathrm{CD} 117^{+} \mathrm{CD} 44^{+}$-scramble in the wound closures, particularly at 48 hours $(p<0.01$, Figure $4 \mathrm{~A}$ and $\mathrm{B})$. In addtion, the effect of silencing HOTAIR on the invasive ability of $\mathrm{CD} 117^{+} \mathrm{CD} 44^{+}$-shHOTAIR was further evaluated by the transwell invasive assay. Figure $4 \mathrm{C}$ indicats the representative images of the cell invasion, which showed a marked decreased in CD117 ${ }^{+} \mathrm{CD} 44^{+}$-shHOTAIR compared with those transfected with $\mathrm{CD} 117^{+} \mathrm{CD} 44^{+}$-scramble (Figure 4D, $p<0.01$ ).

\section{Down-regulated HOTAIR in CD $117^{+} \mathrm{CD} 44^{+} \mathrm{CSC}$ inhibited} the tumor growth and metastasis in the xenograft mouse model

After observing the effects of the down-regulated HOTAIR expression on the migration and invasion of SKOV3 CD117 ${ }^{+} \mathrm{CD} 44^{+}$-shHOTAIR in vitro, we further tested whether this effect would alter the tumorigenicity and metastatic potential of $\mathrm{CD} 117^{+} \mathrm{CD} 44^{+}$-shHOTAIR in the Balb/c nude mice. Figure $5 \mathrm{~A}$ shows the representative images on day 24 after implantation; all the 6 mice generated tumors in 20 days after being injected with $5 \times 10^{4}$ SKOV3 $\mathrm{CD} 117^{+} \mathrm{CD} 44^{+}$ -scramble. The injected mice developed a visible tumor on Day 12, Day 14, Day 16, Day 18, Day 19, and Day 20, respectively. In contrast, 5 of the 6 mice injected with the

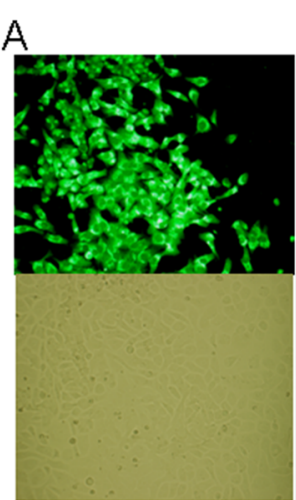

CD $117^{+}$CD $44^{+}$scramble

C

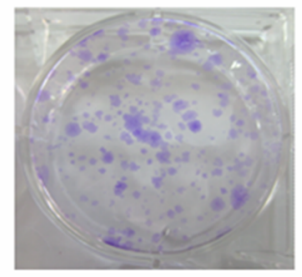

CD117+CD44+scramble

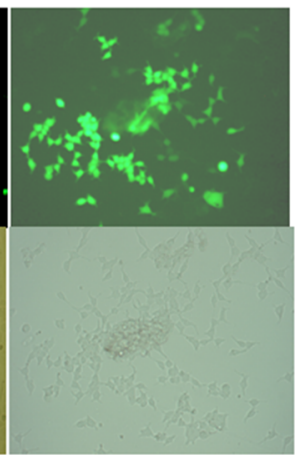

CD117+CD44+shHOTAIR

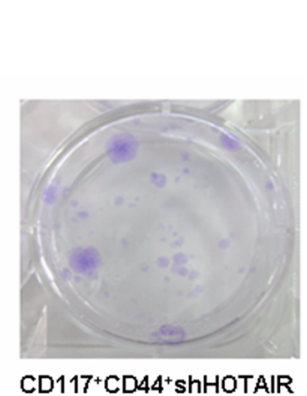

B

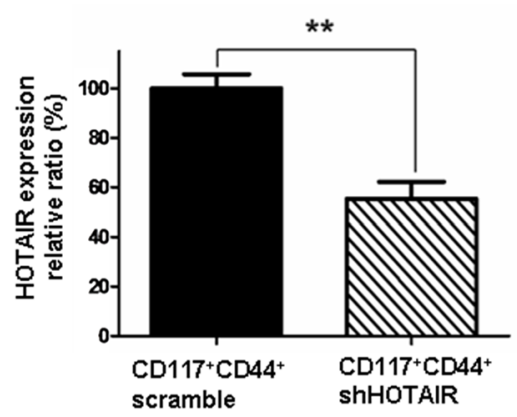

$\mathrm{D}$

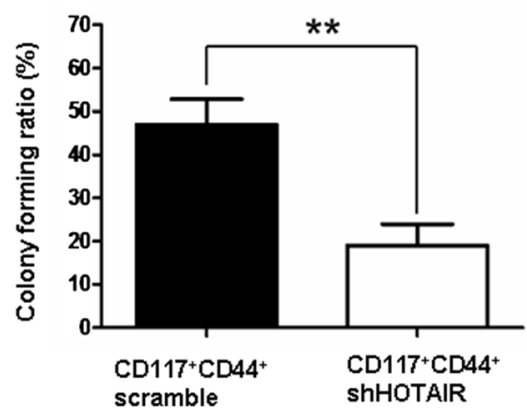

Figure $3 \mathrm{CD} 117^{+} \mathrm{CD} 44^{+}$-shHOTAIR reduced the HOTAIR expression and colony forming potential. A. CD $117^{+} \mathrm{CD} 44^{+} \mathrm{CSCS}$ transfected with the recombinant shHOTAIR or scramble HOTAIR were selected by $800 \mathrm{\mu g} / \mathrm{ml} \mathrm{G} 418$ in two weeks (magnification 200X). Images were taken from a fluorescence microscope (top) and from a light microscope (bottom). B. QRT-PCR analysis of the HOTAIR expression in both CD117 ${ }^{+} \mathrm{CD} 44^{+}$-shHOTAIR and $\mathrm{CD} 117^{+} \mathrm{CD} 44^{+}$-scramble. C. Images of CD $117^{+} \mathrm{CD} 44^{+}$- shHOTAIR and $\mathrm{CD} 117^{+} \mathrm{CD} 44^{+}$-scramble in colony forming assay. D. Statistical analysis of colony forming ratio. ${ }^{*} P<0.01$. 


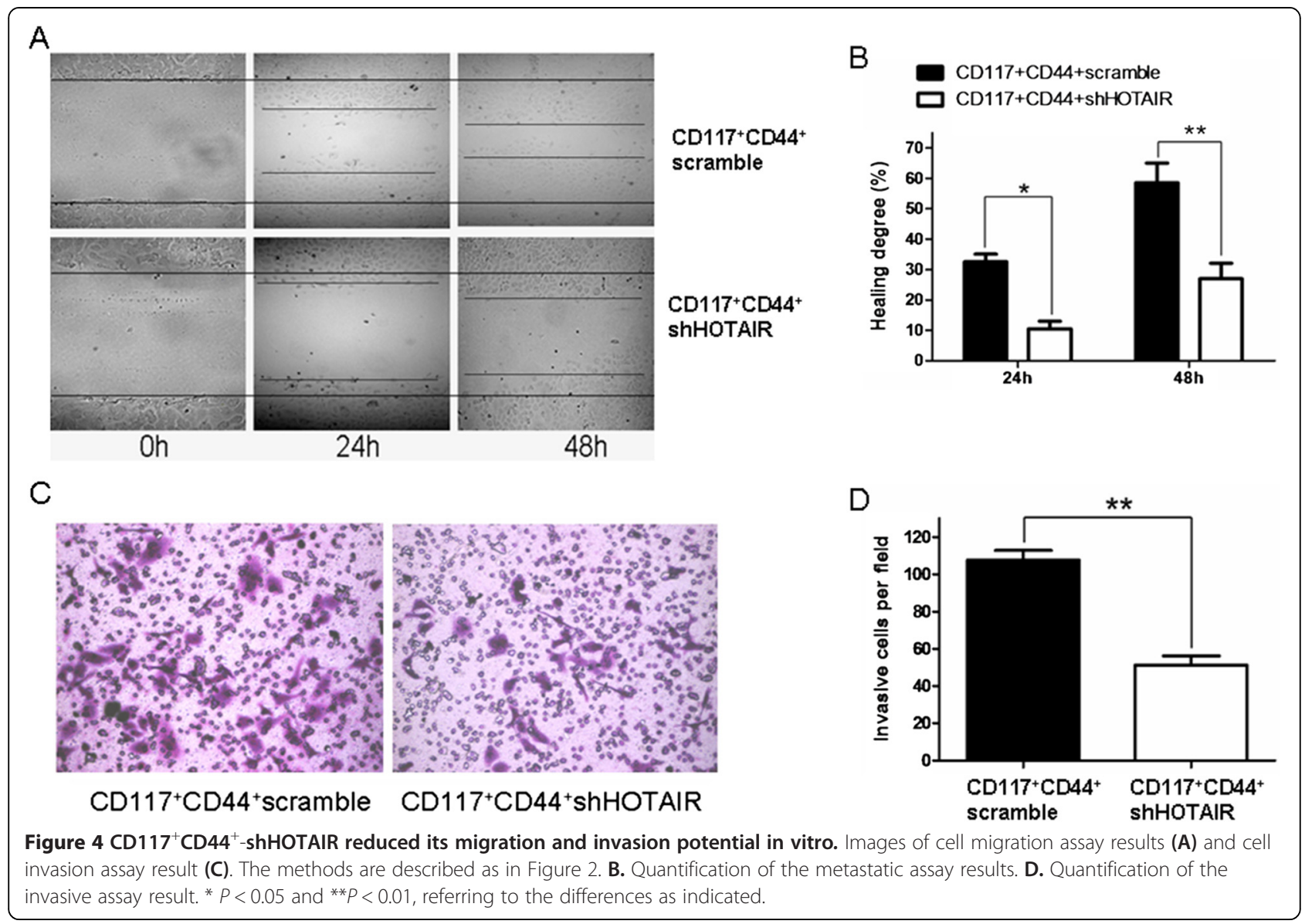

$5 \times 10^{4}$ SKOV3 CD117 ${ }^{+}$CD $44^{+}$-shHOTAIR developed visible tumors on Day 14, Day 16, Day 18, Day 26, and Day 26 , respectively, and the remaining 1 mouse did not develop tumor throughout the 64-day observation period. Figure $5 \mathrm{~B}$ presents the percentages of the tumor-free mice in the two groups. Figure $5 \mathrm{C}$ exhibits the images of the tumor size and quantity. Tumor growth was significantly inhibited in the mice injected with the $\mathrm{CD} 117^{+} \mathrm{CD} 44^{+}$ -shHOTAIR compared with the mice injected with the $\mathrm{CD} 117^{+} \mathrm{CD} 44^{+}$-scramble, and the tumor volume was significantly reduced in the former $(p<0.01)$ (Figure 5D).

To assess the effect of the down-regulation of HOTAIR in $\mathrm{CD} 117^{+} \mathrm{CD} 44^{+}$-shHOTAIR on tumor metastasis, we used H\&E staining to detect if there was tumor cell metastasis in the lung tissues. Compared with the mice injected with $\mathrm{CD} 117^{+} \mathrm{CD} 44^{+}$-scramble, no tumor cell metastasis was found in the lung tissues of the nude mice 64 days after they were injected with the $\mathrm{CD} 117^{+} \mathrm{CD} 44^{+}$-shHOTAIR (Figure 5E). It is thus evident from the results that the tumor cell growth and metastasis were significantly inhibited in the mice injected with $\mathrm{CD} 117^{+} \mathrm{CD} 44^{+}$-shHOTAIR compared with the mice injected with $\mathrm{CD} 117^{+}$ CD $44^{+}$-scramble.

\section{Discussion}

EOC is the most lethal gynecological malignancy in the world and approximately $30 \%$ of cancer patients have died this disease; this emphasizes the need for improved early detection and effective treatment [34]. Evidence has indicated that CSCs are believed to be the 'seed cell' in cancer recurrences and metastases, however, treatments targeted at CSCs have remained to be developed and studied [35]. Increasing evidence supports that CSCs possess mesenchymal characteristics and EMT ability, and that the decreased change in lincRNA HOTAIR was associated with alterations in specific EMT markers concurrent with reduced migratory potential $[6,10,36]$. In this regard, our current study was designed to investigate whether human EOC tissues and SKOV3 $\mathrm{CD} 117^{+} \mathrm{CD} 44^{+} \mathrm{CSCs}$ expresse HOTAIR and whether the decreased change of HOTAIR in human EOC SKOV3 CD $117^{+} \mathrm{CD} 44^{+} \mathrm{CSC}$ are closely associated with the tumorgeniesis and metastasis. Indeed, our data indicated that human EOC patients' tumor tissues and SKOV3 $\mathrm{CD} 117^{+} \mathrm{CD} 44^{+}$CSCs had significantly high expressions of HOTAIR compared with the SKOV3 tumor tissues and SKOV3 non-CD $117^{+} \mathrm{CD} 44^{+} \mathrm{CSCs}$, and that the down-regulated HOTAIR expression in CD117 


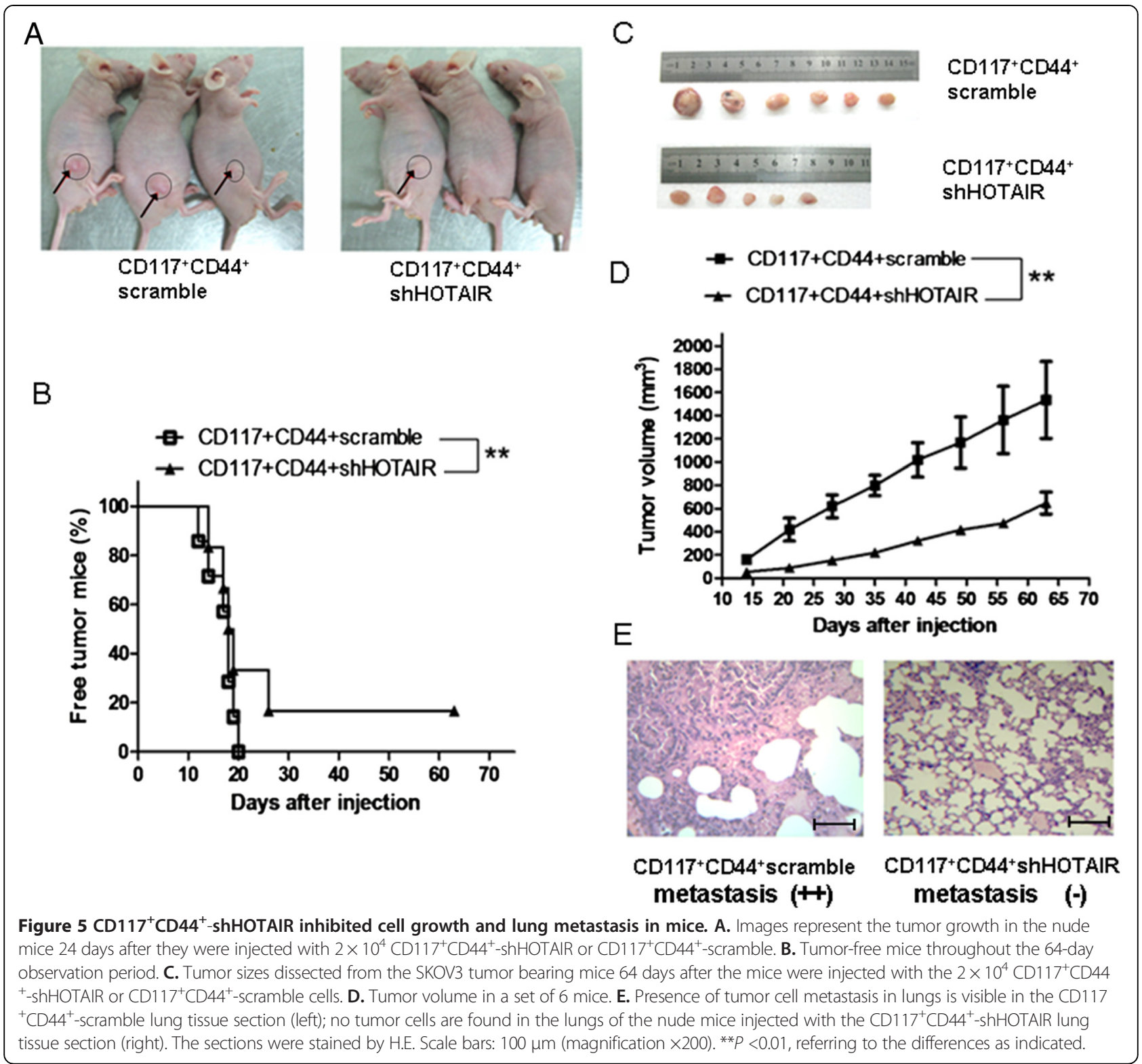

${ }^{+}$CD $44^{+}$-shHOTAIR markedly reduced cellular metastasis and invation in vitro as well as the tumorgeniesis in mice. This efficacy in $\mathrm{CD} 117^{+} \mathrm{CD} 44^{+}$-shHOTAIR was refelected in a lower clonogenic potential, a lower metastatic and invasive potential, and a weeker ability to form tumors in the xenografted mice than in $\mathrm{CD} 138^{-} \mathrm{CD} 34^{-}$-scramble. Importantly, the tumor cell lung metastasis was inhibited in the mice injected with $\mathrm{CD} 117^{+} \mathrm{CD} 44^{+}$-shHOTAIR, whereas the metastatic tumor cells were found in the lungs of the mice injected with $\mathrm{CD} 117^{+} \mathrm{CD} 44^{+}$-scramble.

The evident inhibitory activities in the SKOV3 cells transfected with siHOTAIR were apparently associated with inhibited the HOTAIR expression, which resulted in the increase of the epithelium feature molecule of the E-cadherin expression and reduced mesenchymal feature molecule of the Vimentin expression. The knockdown of the HOTAIR expression in $\mathrm{CD} 117^{+} \mathrm{CD} 44^{+} \mathrm{CSCs}$ may involve the inhibition of EMT of $\mathrm{CD} 117^{+} \mathrm{CD} 44^{+} \mathrm{CSCs}$ and the reduction of cellular migration and invasion potential and tumorgeniesis ability in vitro and in vivo. Nevertheless, the knockdown of the HOTAIR expression mechanism in inhibiting the metastasis of the SKOV3 cells and $\mathrm{CD} 117^{+} \mathrm{CD} 44^{+} \mathrm{CSCs}$ warrants further investigation.

In conclusion, the above-mentioned finding from our study is the first proof for demonstrating the novel role of the dawn-regulated HOTAIR in EOC SKOV3 CD117 
CD $44^{+}$CSCs, for suggesting the inhibitory cellular EMT, and for decreasing decreased the migration and and tumorgeniesis potential of $\mathrm{CD} 117^{+} \mathrm{CD} 44^{+} \mathrm{CSC}$. HOTAIR can be a potential therapeutic target for treatment of EOC patients.

\section{Competing interests}

The authors declare that they have no competing interests.

\section{Authors' contributions}

Jing Wang, Dengyu Chen, and Xiangfeng He carried out the experiments, developed the technique described in the manuscripts, and participated in the writing of the manuscript. Yunxia Zhang, Fangfang Shi, Di wu, Junsong Chen, Ying Zhang, and Fengshu Zhao participated in most of the experiments. Jun Dou contributed to the design of the experiments and to the writing of the manuscript. All authors have read and approved the final manuscript.

\section{Acknowledgements}

This work was supported in part by the National Natural Science Foundation of China (No. 81071769, No. 81202372), Graduate Research and Innovation Projects in Jiangsu Province of China (CXZZ1-0129), and Scientific Research Foundation of Graduated School of Southeast University (No.3224004901).

\section{Author details}

'Department of Gynecology \& Obstetrics, Zhongda Hospital, School of Medicine, Southeast University, Nanjing 210009, China. ${ }^{2}$ Department of Pathogenic Biology and Immunology of School of Medicine, Southeast University, Nanjing 210009, China. ${ }^{3}$ Bengbu Medical School, Department of Microbiology, Bengbu 233030, China. ${ }^{4}$ Department of Medical Oncology, Affiliated Tumor Hospital of Nantong University, Nantong 226361, China. ${ }^{5}$ Department of Oncology, Zhongda Hospital, Southeast University, Nanjing 210009, China

Received: 6 September 2014 Accepted: 10 February 2015 Published online: 25 February 2015

\section{References}

1. Bendoraite A, Knouf EC, Garg KS, Parkin RK, Kroh EM, O'Briant KC, et al. Regulation of miR-200 family microRNAs and ZEB transcription factors in ovarian cancer: Evidence supporting a mesothelial-to-epithelial transition. Gynecol Oncol. 2010;116:117-25.

2. Ho CM, Chang SF, Hsiao CC, Chien TY, Shih DT. Isolation and characterization of stromal progenitor cells from ascites of patients with epithelial ovarian adenocarcinoma. J Biomed Sci. 2012;19:23.

3. Cannistra S-A. Cancer of the ovary. N Eng J Med. 2004;351:2519-29.

4. Dou J, Jiang CL, Wang J, Zhang X, Zhao F, Hu W, et al. Using ABCG2- moleculeexpressing side population cells to identify cancer stem-like cells in a human ovarian cell line. Cell Biol Int. 2011;35:227-34.

5. Vaibhav S, Robert HS. Potential for therapeutic targeting of tumor stem cells. Cancer Sci. 2010;101:16-21.

6. Chen D, Zhang Y, Wang J, Chen J, Yang C, Cai K, et al. MicroRNA-200C overexpression inhibits tumorigenicity and metastasis of $\mathrm{CD} 117^{+} \mathrm{CD} 44^{+}$ ovarian cancer stem cells by regulating epithelial-mesenchymal transition. J Ovarian Res. 2013;6:50.

7. Yang C, Xiong F, Wang J, Dou J, Chen J, Chen D, et al. Anti-ABCG2 monoclonal antibody in combination with paditaxel-nanoparticles against cancer stem-like cell activity in multiple myeloma. Nanomedicine-(Lond). 2014;9:45-60.

8. John LR, Kertesz M, Wang JK, Squazzo SL, Xu X, Brugmann SA, et al. Functional demarcation of active and silent chromatin domains in human HOX loci by noncoding RNAs. Cell. 2007;129:1311-23.

9. Wilusz JE, Sunwoo H, Spector DL. Long noncoding RNAs: functional surprises from the RNA world. Genes Dev. 2009:23:1494-504.

10. Gupta RA, Shah N, Wang KC, Kim J, Horlings HM, Wong DJ, et al. Long non-coding RNA HOTAIR reprograms chromatin state to promote cancer metastasis. Nature. 2010;464:1071-6.

11. Zhang H, Cai K, Wang J, Wang X, Cheng K, Shi F, et al. MiR-7, inhibited by lincRNA HOTAIR, directly inhibites SETDB1 and reverses the EMT of breast cancer stem cells by downregulating the STAT3 pathway. Stem Cell. 2014;32:2858-68
12. Geng YJ, Xie SL, Li Q, Ma J, Wang GY. Large intervening non-coding RNA HOTAIR is associated with hepatocellular carcinoma progression. J Int Med Res. 2011;39:2119-28.

13. Ishibashi M, Kogo R, Shibata K, Sawada G, Takahashi Y, Kurashige J, et al. Clinical significance of the expression of long non-coding RNA HOTAIR in primary hepatocellular carcinoma. Oncol Rep. 2013;29:946-50.

14. Kogo R, Shimamura T, Mimori K, Kawahara K, Imoto S, Sudo T, et al. Long noncoding RNA HOTAIR regulates polycomb- dependent chromatin modification and is associated with poor prognosis in colorectal cancers. Cancer Res. 2011;71:6320-6.

15. Kim K, Jutooru I, Chadalapaka G, Johnson G, Frank J, Burghardt R, et al. HOTAIR is a negative prognostic factor and exhibits pro-oncogenic activity in pancreatic cancer. Oncogene. 2013;32:1616-25.

16. Niinuma T, Suzuki H, Nojima M, Nosho K, Yamamoto H, Takamaru H, et al, Upregulation of miR-196a and HOTAIR drive malignant character in gastrointestinal stromal tumors. Cancer Res. 2012;72:1126-36.

17. Chen DY. Study of therapy of ovarian cancer and CSCs by targeted regulating miR-200c-ZEB1 feedback loop. Southeast University, China: Dissertation For the Academic Degree of Doctor of Medical Science; 2013.

18. Qiu JJ, Lin YY, Ye LC, Ding JX, Feng WW, Jin HY, et al. Overexpression of long non-coding RNA HOTAIR predicts poor patient prognosis and promotes tumor metastasis in epithelial ovarian cancer. Gynecol Oncol. 2014;134:121-8.

19. Yang G, Zhang S, Gao F, Liu Z, Lu M, Peng S, et al. Osteopontin enhances the expression of HOTAIR in cancer cells via IRF1. Biochim Biophys Acta. 1839;2014:837-48.

20. Dou J, Pan M, Wen P, Li Y, Tang Q, Chu L, et al. Isolation and identification of cancer stem-like cells from murine melanoma cell lines. Cell Mol Immunol. 2007:4:467-72.

21. Zhang S, Balch C, Chan MW, Lai HC, Matei D, Schilder JM, et al. Identification and characterization of ovarian cancer-initiating cells from primary human tumors. Cancer Res. 2008;68:4311-20.

22. Chen J, Wang J, Chen DY, Yang J, Yang C, Zhang Y, et al. Evaluation of characteristics of CD117+CD44+ ovarian cancer stem cells in three dimensional basement membrane extract scaffold versus two dimensional monocultures. BMC Cell Biol. 2013;14:7.

23. Arnhold S, Glüer S, Hartmann K, Raabe O, Addicks K, Wenisch S, et al. Amniotic-fluid stem cells: growth dynamics and differentiation potential after a CD-117-based selection procedure. Stem Cells Int. 2011;23:715341.

24. Luo L, Zeng J, Liang B, Zhao Z, Sun L, Cao D, et al. Ovarian cancer cells with the CD117 phenotype are highly tumorigenic and are related to chemotherapy outcome. Exp Mol Pathol. 2011;91:596-602.

25. Choi YP, Shim HS, Gao MQ, Kang S, Cho NH. Molecular portraits of intratumoral heterogeneity in human ovarian cancer. Cancer Lett. 2011;307:62-71.

26. Dou J, He XF, Liu Y, Wang Y, Zhao F, Wang X, et al. Effect of downregulation of ZEB1 on vimentin expression, tumour migration and tumourigenicity of melanoma B16F10 cells and CSCs. Cell Biol Int. 2014;38:452-61.

27. Sieh S, Taubenberger AV, Rizzi SC, Sadowski M, Lehman ML, Rockstroh A, et al. Phenotypic characterization of prostate cancer LNCaP cells cultured within a bioengineered microenvironment. PLoS One. 2012;7:e40217.

28. He X, Wang J, Zhao F, Yu F, Chen D, Cai K, et al. Antitumor efficacy of viable tumor vaccine modified by heterogenetic ESAT- 6 antigen and cytokine IL-21 in melanomatous mouse. Immunol Res. 2012;52:240-9.

29. Shen B, Chu ES, Zhao G, Man K, Wu CW, Cheng JT, et al. PPARgamma inhibits hepatocellular carcinoma metastases in vitro and in mice. Br J Cancer. 2012;106:1486-94.

30. Ngora H, Galli UM, Miyazaki K, Zöller M. Membrane-bound and exosoma metastasis- associated C44A promotes migration by associating with the $a(6) \beta(4)$ integrin and MT1-MMP. Neoplasia. 2012;14:95-107.

31. Hu K, Dou J, Yu F, He X, Yuan X, Wang Y, et al. An ocular mucosal administration of nanoparticles containing DNA vaccine pRSC-gD-IL-21 confers protection against mucosal challenge with herpes simplex virus type 1 in mice. Vaccine. 2011;29:1455-62.

32. Hu W, Wang J, Dou J, He X, Zhao F, Jiang C, et al. Augmenting therapy of ovarian cancer efficacy by secreting IL-21 human umbilical cord blood stem cells in nude mice. Cell Transplant. 2011;20:669-80.

33. Zhang Y, Wang J, Ren M, Li M, Chen D, Chen J, et al. Gene therapy of ovarian cancer using IL-21-secreting human umbilical cord mesenchymal stem cells in nude mice. J Ovarian Res. 2014;7:8. 
34. Wakahashi S, Sudo T, Oka N, Ueno S, Yamaguchi S, Fujiwara K, et al. VAV1 represses $\mathrm{E}$-cadherin expression through the transactivation of snail and slug: a potential mechanism for aberrant epithelial to mesenchymal transition in human epithelial ovarian cancer. Transl Res. 2013;162:181-90.

35. Luo X, Dong Z, Chen Y, Yang L, Lai D. Enrichment of ovarian cancer stem-like cells is associated with epithelial to mesenchymal transition through an miRNA-activated AKT pathway. Cell Prolif. 2013;46:436-46.

36. Khatri N, Rathi M, Baradia D, Trehan S, Misra A. In vivo delivery aspects of miRNA, shRNA and siRNA. Crit Rev Ther Drug Carrier Syst. 2012;29:487-527.

\section{Submit your next manuscript to BioMed Central} and take full advantage of:

- Convenient online submission

- Thorough peer review

- No space constraints or color figure charges

- Immediate publication on acceptance

- Inclusion in PubMed, CAS, Scopus and Google Scholar

- Research which is freely available for redistribution 